\section{A study on the disaster medical response during the Mauna Ocean Resort gymnasium collapse}

\author{
Myeong-il Cha', Gi Woon Kim², Chu Hyun Kim³ ${ }^{3}$ Minhong Choa ${ }^{4}$, \\ Dai Hai Choi ${ }^{5}$, Inbyung Kim ${ }^{1}$, Soon Joo Wang ${ }^{6}$, In Sool Yoo \\ Han Deok Yoon ${ }^{8}$, Kang Hyun Lee ${ }^{9}$, Suck Ju Cho ${ }^{10}$, Tag Heo ${ }^{11}$, \\ Eun Seog Hong ${ }^{12}$
}

'Department of Emergency Medicine, Myongji Hospital, Goyang, Korea

${ }^{2}$ Department of Emergency Medicine, Sooncheonhyang University Bucheon Hospital, Bucheon, Korea ${ }^{3}$ Department of Emergency Medicine, Seoul Paik Hospital, Inje University College of Medicine, Seoul, Korea ${ }^{4}$ Center for Disaster Relief Training and Research, Severance Hospital, Yonsei University College of Medicine, Seoul, Korea

${ }^{5}$ Department of Emergency Medicine, Dongguk University Gyeongju Hospital, Gyeongju, Korea

${ }^{6}$ Department of Emergency Medicine, Hallym University Dongtan Sacred Heart Hospital, Hwaseong, Korea ${ }^{7}$ Department of Emergency Medicine, Chungnam National University Hospital, Daejeon, Korea

${ }^{8}$ National Emergency Medical Center, National Medical Center, Seoul; Department of Emergency Medicine,

${ }^{9}$ Yonsei University Wonju College of Medicine, Wonju, Korea

${ }^{10}$ Department of Emergency Medicine, Pusan National University Hospital, Pusan, Korea

${ }^{11}$ Department of Emergency Medicine, Chonnam National University Hospital, Gwangju, Korea

${ }^{12}$ Department of Emergency Medicine, Ulsan University Hospital, University of Ulsan College of Medicine, Ulsan, Korea

Objective To investigate and document the disaster medical response during the Gyeongju Mauna Ocean Resort gymnasium collapse on February 17, 2014.

Methods Official records of each institution were verified to select the study population. All the medical records and emergency medical service run sheets were reviewed by an emergency physician. Personal or telephonic interviews were conducted, without a separate questionnaire, if the institutions or agencies crucial to disaster response did not have official records or if information from different institutions was inconsistent.

Results One hundred fifty-five accident victims treated at 12 hospitals, mostly for minor wounds, were included in this study. The collapse killed 10 people. Although the news of collapse was disseminated in 4 minutes, dispatch of 4 disaster medical assistance teams took at least 69 minutes to take the decision of dispatch. Four point five percent were treated at the accident site, $56.7 \%$ were transferred to 2 hospitals that were nearest to the collapse site, and $42.6 \%$ were transferred to hospitals that were poorly prepared to handle disaster victims.

Conclusion In the Gyeongju Mauna Ocean Resort gymnasium collapse, the initial triage and distribution of patients was inefficient and medical assistance arrived late. These problems had also been noted in prior mass casualty incidents.

Keywords Disasters; Mass casualty incidents; Medical assistance; Social networking
elSSN: 2383-4625

Received: 18 January 2016

Revised: 24 March 2016

Accepted: 5 May 2016

Correspondence to: Inbyung Kim Department of Emergency Medicine, Myongji Hospital, 55 Hwasu-ro 14beon-gil, Deogyang-gu, Goyang 10475, Korea

E-mail:kiminbyung@gmail.com

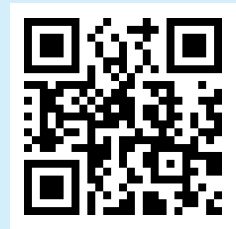

How to cite this article:

Cha Mi, Kim GW, Kim CH, Choa M, Choi DH, Kim I, Wang SJ, Yoo IS, Yoon HD, Lee KH, Cho SJ, Heo T, Hong ES. A study on the disaster medical response during the Mauna Ocean Resort gymnasium collapse. Clin Exp Emerg Med 2016;3(3):165-174.

This is an Open Access article distributed under the terms of the Creative Commons Attribution Non-Commercial License (http:// creativecommons.org/licenses/by-nc/4.0/). 


Capsule
Wummary is already known
$\begin{aligned} & \text { Although published reports on previous disasters have pointed out the absence of initial field triage or insufficient hos- } \\ & \text { pital transport dispersion, no significant improvements have been made. }\end{aligned}$
$\begin{aligned} & \text { What is new in the current study } \\ & \text { The Mauna Ocean Resort gymnasium collapsed on February 17, 2014, at 21:06. This was a mass casualty incident with } \\ & \text { at least } 155 \text { casualties. Field triage and distribution of transportation at the site were not properly conducted, like other } \\ & \text { previous disasters. However, this highlighted a need for public safety and practical preparation in the form of a disaster } \\ & \text { response system. }\end{aligned}$

\section{INTRODUCTION}

Recently, there have been 2 major disasters in Korea: the Mauna Ocean Resort gymnasium collapse and sinking of the Sewol ferry. These disasters highlighted a need for public safety and practical preparation in the form of a disaster response system. Although published reports on mass disasters have pointed out the absence of initial field triage or insufficient hospital transport dispersion, $^{1-8}$ no significant improvements have been made. In the aftermath of both disasters, this lack of preparation was prominently featured in media reports. ${ }^{9,10}$

The Mauna Ocean Resort gymnasium collapsed on February 17, 2014. Nine days later, the Korean Society of Emergency Medicine formed a committee to investigate the incident. The committee was tasked with writing a report, which could be used as a reference for the development of a disaster medical response system, and proposing policy directions for improving the current system. The investigation included examination of the fire departments, paramedics, disaster medical assistance teams (DMATs), public health centers, medical institutions, and government agencies that were active during the gymnasium collapse. This manuscript summarizes the findings of this investigation.

\section{METHODS}

\section{Study population}

Although the death toll from various aforementioned agencies matched, the total number of casualties differed. To resolve this discrepancy, the 115 patients listed in the official report of the fire station ${ }^{11}$ were examined first followed by the examination of patients listed in the report issued by the National Emergency Medical Center. ${ }^{12}$ Among the 19 hospitals involved in disaster victim care, we could obtain medical records only from 11 hospitals and could recognize personal details of the patients in the records from 2 hospitals. Some patients were recorded on the emergency medical service (EMS) run sheets of the hospitals but not documented in their medical records because they left the hospital before receiving medical care. After filtering out repetitive information due to transfer of patients, the study population comprised 155 patients treated at 12 hospitals.

\section{Study design and data collection}

The disaster response of each institution was comprehensively examined using the official reports issued by the institution. ${ }^{11,12}$ Presentations from the Korean Society of Emergency Medicine Spring Conference and the Korean Society of Disaster Medicine Conference were also used as references; although the conference speakers had been directly involved in the disaster response, they had not been a part of any official report. They were also interviewed in person as mentioned below.

The medical records of 11 out of 12 hospitals were examined (Table 1). Photocopies of EMS run sheets maintained at 5 of the hospitals were examined. Five other hospitals did not maintain EMS run sheets because they did not receive any patient via an ambulance. One hospital did not provide medical records (Table 1). Information in the medical records included the time of visit, tri-

Table 1. Hospital investigation

\begin{tabular}{ccccc}
\hline Regions & Hospitals & $\begin{array}{c}\text { No. of medical } \\
\text { records }\end{array}$ & $\begin{array}{c}\text { No. of EMS } \\
\text { run sheets }\end{array}$ & $\begin{array}{c}\text { Type of } \\
\text { interview }\end{array}$ \\
\hline Ulsan Metro- & Hospital A & 39 & 23 & Personal \\
politan City & Hospital B & 43 & 23 & Personal \\
& Hospital C & 8 & 6 & - \\
& Hospital D & 4 & 4 & - \\
& Hospital E & 3 & Not provided & Personal \\
Gyeongju city & Hospital F & 17 & No patient & Personal \\
& Hospital G & 8 & 3 & Personal \\
& Hospital H & 8 & No patient & Personal \\
& Hospital I & 6 & No patient & Personal \\
Busan Metro- & Hospital J & 20 & No patient & - \\
politan City & Hospital K & 3 & No patient & -
\end{tabular}

EMS, emergency medical service. 
Table 2. Investigation summary as per the disaster response stages

\begin{tabular}{|c|c|}
\hline Stages & Investigation points \\
\hline $\begin{array}{l}\text { Recognition of the accident, propagation of the situation, and dispatch of } \\
\text { advanced medical post/DMAT }\end{array}$ & $\begin{array}{l}\text { Time of accident information } \\
\text { Path of accident information } \\
\text { Time of identifying the scale of casualties } \\
\text { Propagation path of the situation } \\
\text { Time of dispatch request } \\
\text { Path of dispatch request } \\
\text { Decision-making of the dispatch } \\
\text { Dispatch decision time } \\
\text { Dispatch preparation time } \\
\text { Dispatch time }\end{array}$ \\
\hline Field disaster medical activity & $\begin{array}{l}\text { Scene arrival time } \\
\text { Dispatch equipment and personnel } \\
\text { Field triage, first aid, and hospital selection } \\
\text { Command system of advanced medical post } \\
\text { Field disaster medical activity report system communication tool } \\
\text { Field access control } \\
\text { Inquiry path to determine the status of hospital beds } \\
\text { Field propagation path of transportation guidelines }\end{array}$ \\
\hline Inpatient care at the hospital & $\begin{array}{l}\text { Time of hospital arrival } \\
\text { Triage results } \\
\text { Means of hospital arrival } \\
\text { Initial vital signs } \\
\text { Treatment outcome } \\
\text { Diagnosis } \\
\text { Major examinations and treatment } \\
\text { Status of hospitalization } \\
\text { Days of hospital stay } \\
\text { Medical staff activation time } \\
\text { Response to multiple casualties }\end{array}$ \\
\hline
\end{tabular}

DMAT, disaster medical assistance team.

age results, vehicle for hospital visit, vital signs, treatment outcome, chief complaints, diagnosis, examination and treatment history, discharge date and time, and status of hospitalization. The EMS run sheets contained information regarding the scene arrival time, hospital arrival time, triage result, ambulance affiliation, destination hospital, vital signs, chief complaints, and first aid history. All the medical records and EMS run sheets were reviewed by the same emergency physician.

Personal or telephonic interviews of the officials of the government institutions, hospitals, and fire institutions that participated in the disaster response were conducted. Officials from the Ministries of Health and Welfare, and Public Safety and Security, and the Gyeongju Public Health Center, which do not routinely maintain official records, were interviewed. Interviews were also conducted for officials from the 4 hospitals located in Gyeongju city, 2 hospitals that treated the most disaster victims, and the level 1 trauma center closest to the collapse site. In addition, we conducted interviews to investigate the medical activities in the field, and to confirm events that were not recorded in detail in the official reports or were inconsistent among the institutions with DMATs, National Emergency Medical Center (including emergen- cy medical information centers), and private ambulance services. Extra questionnaires were not used. The inquiry details are summarized in Table 2.

\section{Statistical analysis}

Since all triage results could not be verified from the hospital records, the injury severity score (ISS) was used to evaluate the injury severity of the trauma patients. The score could not be calculated only from the information of the medical records; therefore, the Excess Mortality Ratio-adjusted ISS (EMR ISS) ${ }^{13}$ based on the International Classification of Diseases version 10 (ICD-10) codes, was used.

\section{RESULTS}

The Mauna Ocean Resort gymnasium collapsed on February 17, 2014, at 21:06." A section of the roof collapsed due to the snow that had accumulated during the previous 10 days. At the time of collapse, a welcome party for college freshmen of Busan University of Foreign Studies was in progress inside the gym. Four hundred participants were able to escape. Rescue access to the resort 
Table 3. Incident response by timelines

\begin{tabular}{lc}
\hline Time & \multicolumn{1}{c}{ Rescue operation } \\
\hline Feb 17 & Gyeongbuk Regional Fire and Disaster Headquarter situation room received \\
21:06 & the first report call \\
$21: 09$ & $\begin{array}{c}\text { Collapse incident notification through broadcasting at the same time by all } \\
\text { fire stations in the province, and standby of rescue teams and paramedics }\end{array}$
\end{tabular}

21:11 Dispatch request to Ulsan Regional Fire and Disaster Headquarter and National 119 Rescue Headquarter

Situation propagation to 25 institutions such as Gyeongju city hall, police agencies, and others

Report to the Ministry of Public Safety and Security

21:14 Report to the director of the Gyeongbuk Regional Fire and Disaster Headquarter

21:19 Report to the vice governor of Gyeongbuk province

Feb 17 Situation propagation from Gyeongbuk Regional Fire and Disaster Head-

21:10 quarter situation room to Gyeongbuk Emergency Medical Information Center

21:11 Dispatch request for hospital ambulance and private ambulance services from Gyeongbuk Regional Fire and Disaster Headquarter situation room

21:16 National Emergency Medical Center recognized the situation Gyeongbuk Regional Emergency Medical Information Center contacted the provincial government of Gyeongbuk

21:29 Start of operation by the National Emergency Medical Center situation room

21:30 Report to the Ministry of Health and Welfare

21:32 Regional preliminary alert level 2

21:33 A staff member of the Gyeongbuk Emergency Medical Information Center was dispatched to the scene

21:36 First ambulance arrived at the scene

21:37 The head of Gyeongju Public Health Center learnt about the incident through media

Incident propagation from the mayor of Gyeongju city

21:38 The director of the Gyeongbuk Regional Fire and Disaster Headquarter took command of the situation room

21:40 First rescue team arrived at the scene

21:43 Emergency Response Team of Gyeongju fire station arrived at the scene, and took command

22:00 Ministry of Public Safety and Security requested Ulsan University Hospital DMAT dispatch

22:06 Ministry of Public Safety and Security requested Andong Hospital for DMAT dispatch

22:08 Ministry of Public Safety and Security requested the National Emergency Medical Center for DMAT dispatch

22:10 A staff member of the Gyeongbuk Emergency Medical Information Center arrived at the entrance of the resort

Head of Gyeongju Public Health Center arrived at the entrance of the resort

22:15 Decision of DMAT dispatch from the Ministry of Health and Welfare

22:16 Ministry of Health and Welfare requested DMAT dispatch from Andong Hospital and Kyungpook National University Hospital

22:25 Advance team of Andong Hospital DMAT dispatch

22:26 Arrival of the staff of Gyeongbuk Emergency Medical Information Center and head of Gyeongju Public Health Center at the gym (disaster scene)

22:30 Arrival of the director of the Gyeongju fire station, who took command

22:33 Disaster medical support-related Kakao Talk chat room opened

22:35 Advance team of Ulsan University Hospital DMAT dispatch Andong Hospital DMAT headquarters dispatch

22:40 Emergency Rescue Control Headquarters of Gyeongju fire station arrived at the scene, and installed a field command post 
Table 3. Continued

\begin{tabular}{|c|c|c|c|}
\hline Time & Rescue operation & Time & Disaster medical operation \\
\hline & & 23:00 & $\begin{array}{l}\text { Advance team of Ulsan University Hospital DMAT arrived at the scene } \\
\text { Kyungpook National University Hospital DMAT dispatch }\end{array}$ \\
\hline \multirow[t]{3}{*}{$23: 20$} & $\begin{array}{l}\text { Arrival of the director of the Gyeongbuk Regional Fire and Disaster } \\
\text { Headquarter, who took command }\end{array}$ & & \\
\hline & & $23: 40$ & Advanced medical post installation completed \\
\hline & & $\begin{array}{c}\text { Feb } 18 \\
00: 20\end{array}$ & DMATs treated 2 patients (1 dead after CPR) \\
\hline \multirow[t]{5}{*}{$\begin{array}{l}\text { Feb } 18 \\
00: 29\end{array}$} & $\begin{array}{l}\text { The director of the Gyeongbuk Regional Fire and Disaster Headquarter } \\
\text { presided the field command post interagency meeting }\end{array}$ & & \\
\hline & & $01: 00$ & $\begin{array}{l}\text { Andong Hospital DMAT arrived at the scene } \\
\text { Mayor of Gyeongju city requested DMAT dispatch from Dongguk University } \\
\text { Gyeongju Hospital }\end{array}$ \\
\hline & & $01: 05$ & Kyungpook National University Hospital DMAT arrived at the scene \\
\hline & & $01: 17$ & Kyungpook National University Hospital DMAT returned \\
\hline & & $01: 40$ & Andong Hospital DMAT joined the advanced medical post \\
\hline \multirow[t]{8}{*}{$01: 55$} & The final victim rescue completed & & \\
\hline & & 02:05 & One patient died after CPR \\
\hline & & 02:10 & One male patient returned home after treatment \\
\hline & & 02:12 & One female patient returned home after treatment \\
\hline & & 02:15 & One female patient returned home after treatment \\
\hline & & $02: 56$ & One male patient returned home after treatment \\
\hline & & 05:00 & Dongguk University Gyeongju Hospital DMAT dispatch \\
\hline & & 06:00 & Dongguk University Gyeongju Hospital DMAT arrived \\
\hline \multirow[t]{3}{*}{ 06:05 } & Emergency duty released & & \\
\hline & & 07:20 & Withdrawal command to advanced medical post \\
\hline & & 08:30 & Withdrawal after cleaning up the site \\
\hline
\end{tabular}

DMAT, disaster medical assistance team; CPR, cardiopulmonary resuscitation.

was impeded due to the lack of snow removal from the one-lane entry road, and because of ongoing snowfall and cold temperature $\left(2.8^{\circ} \mathrm{C}\right)$. The organized rescue and emergency activities as per the time lines are indicated in Table 3.

\section{Awareness of the accident and response}

Almost immediately after the roof collapse, the situation room of the Gyeongbuk Regional Fire and Disaster Headquarters received the first report of the disaster. They notified the Gyeongbuk Regional Emergency Medical Information Center within 4 minutes at 21:10. The information center notified the National Emergency Medical Center at 21:16, which in turn notified the Ministry of Health and Welfare at 21:30. By 22:00, the news of the disaster had been sent to the Ulsan and Daegu emergency medical information centers (the DMATs of the Ulsan University Hospital and Kyungpook [Gyeongbuk] National University Hospital). The DMATs were requested to standby pending dispatch to the site of collapse (Fig. 1). Although the official DMAT of Gyeongbuk province was located in Andong Hospital, the nearest DMATs were in UIsan and Daegu. The situation room of Gyeongbuk Regional Fire and Disaster Headquarters also notified Gyeongju city at 21:11. When the mayor of Gyeongju city contacted the public health center to initiate emergency assistance at 21:37, the center head was already aware of the incident through media and had already decided to dispatch aid. The Gyeongbuk Health Policy Division of Gyeongbuk province had also requested aid from the public health center at 21:56 (Fig. 1).

Between 22:00 and 22:06, the Ministry of Public Safety and Security contacted the emergency department of Ulsan University Hospital and Andong Hospital to request DMAT response. The request was ignored. This prompted the ministry to contact the $\mathrm{Na}$ tional Emergency Medical Center with the same request. The Emergency Healthcare Department of the Ministry of Health and Welfare was aware of the request. A DMAT was dispatched at 22:15 (Fig. 1). Ulsan University Hospital had also initiated DMAT dispatch preparations immediately upon notification of the disaster at 22:00. Andong Hospital learnt about the incident through television reports at 21:30, and had also immediately initiated a DMAT dispatch. The team was finally dispatched following the request from the Ministry of Health and Welfare at 22:16. Kyungpook National University Hospital had started to prepare for DMAT dispatch after a request from the Ministry of Health and Welfare between 22:00 and 22:16 (Fig. 1). 


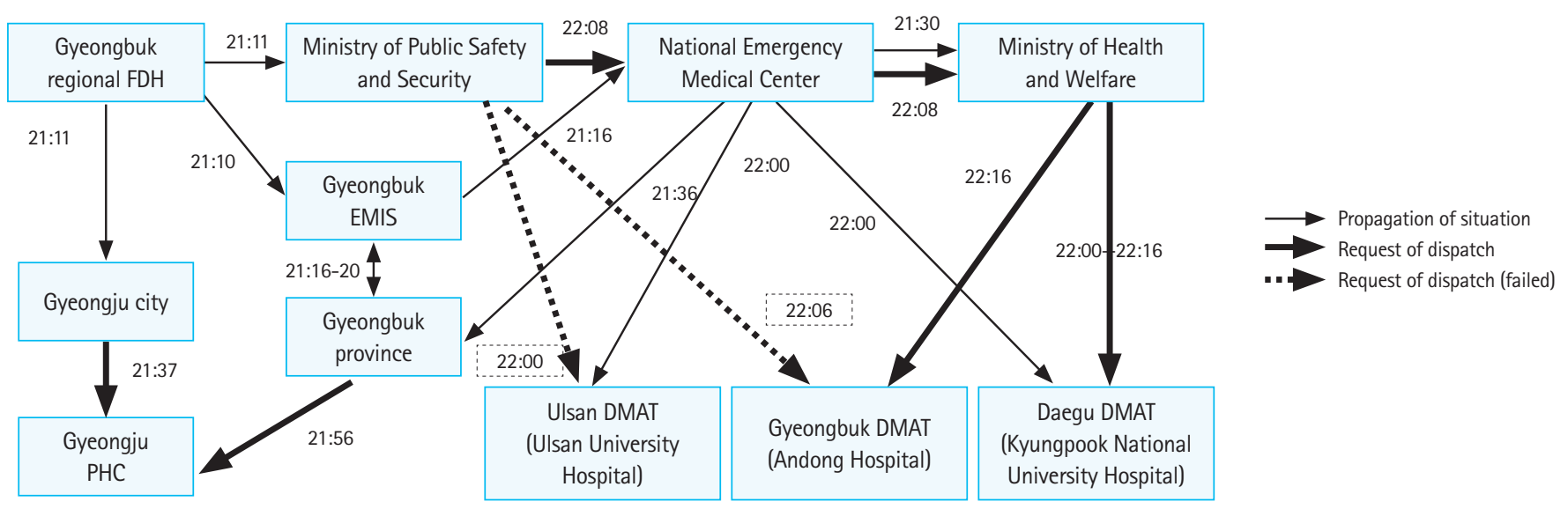

Fig. 1. The path of situation propagation and disaster medical assistance team dispatch. FDH, fire and disaster headquarter; EMIS, emergency medical information center; PHC, public health center; DMAT, disaster medical assistance team.

\section{Field disaster medical activity}

Field disaster medical activities were initiated after the arrival of paramedics at the collapse site. The first ambulance from Gyeongju fire station arrived at the scene at 21:36 and administered first aid to the victims at the entrance of the resort. Ambulance personnel reported the field conditions. At 21:43, the fire station's emergency response team arrived at the scene. A fire investigator in the response team, who was a class 2 emergency medical technician, conducted field triage, although it was not referred to as triage, involving victims who had walked unaided from the gymnasium. Ambulances from other fire stations continued to arrive, and there were 9 ambulances on the site by 22:10. Private ambulances from Ulsan had also arrived, although the time of their arrival is unknown.

The head of Gyeongju Public Health Center and staff of Gyeongbuk Regional Emergency Medical Information Center arrived at the disaster scene at 22:10 and met in the front of the gym at $22: 26$. While the ambulatory victims were treated by the doctors from the public health center, 7 to 8 rescued victims were carried on stretchers from the gym. They were triaged and taken to nearby hospitals for further care. Sixty-six patients had been transferred before the arrival of the head of the public health center and staff of the information center, and 88 patients were moved before the completion of advanced medical post installation (Fig. 2).

The staff of the information center tried to select a site for the installation of an advanced medical post. However, the selection proved difficult because it required coordination with the fire department activities. Eventually, the advance team of Ulsan University Hospital DMAT commenced the installation of the advanced medical post at 23:00 without consultation with the fire officials. Installation was completed by 23:40 (Table 3). Seven patients were taken to the advanced medical post. Two patients were de-

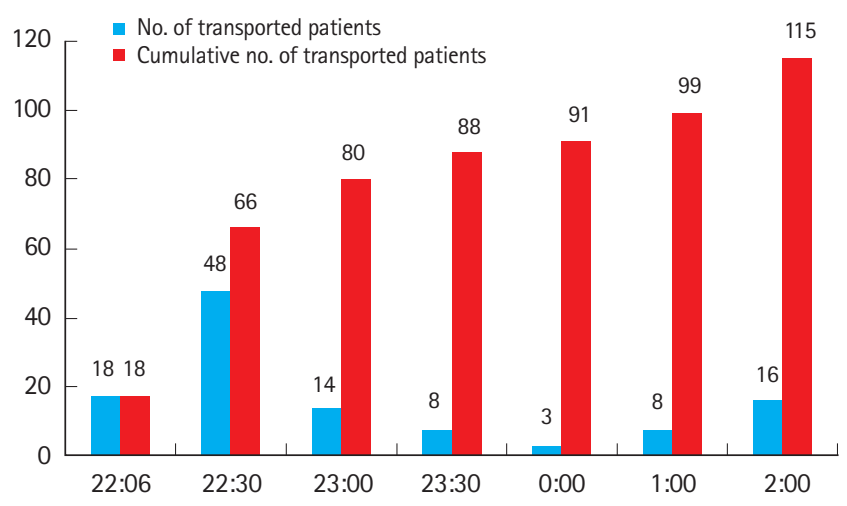

Fig. 2. Patient transport status as per timelines.

clared dead after attempts of cardiopulmonary resuscitation, 1 patient was severely injured, and 4 had minor wounds. Triage tag were not used and no medical treatment records were maintained.

Kyungpook National University Hospital DMAT arrived at the entrance of the resort at 01:05; however, it withdrew at 01:17 because of bad weather and road conditions. Andong Hospital DMAT arrived at the scene at 01:40 and aided the activities at the advanced medical post. Dispatch of Dongguk University Gyeongju Hospital DMAT had been requested by the mayor of Gyeongju city at 01:00. This dispatch had not been acknowledged by the head of Gyeongju Public Health Center or the situation room of the National Emergency Medical Center. Eventually, the Dongguk University Gyeongju Hospital DMAT arrived at the scene at 05:00; there was no cooperation with other DMATs in the field. Evacuation of the advanced medical post was ordered by Gyeongbuk at 07:20, and withdrawal was complete at 08:30. In all, 39 DMAT members from 4 DMAT units were dispatched to the scene.

The director of the advanced medical post was the head of Gyeongju Public Health Center. Medical treatment was led by UI- 


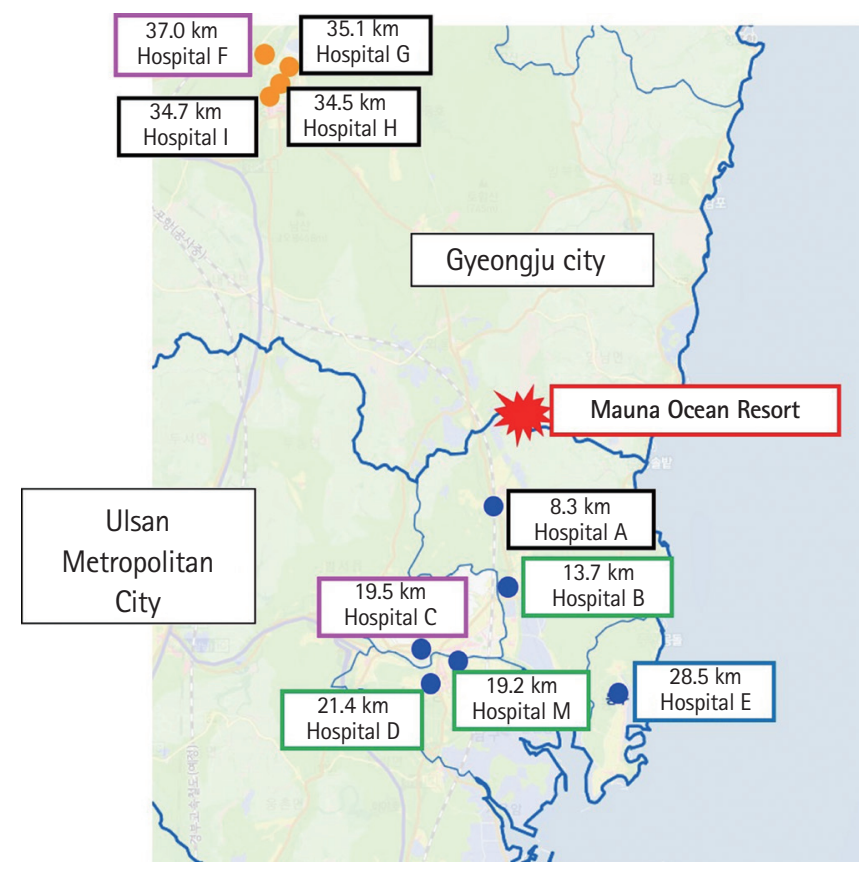

Fig. 3. Location of the hospitals that received the accident victims.

san University Hospital DMAT. The field situation was reported to the temporary situation room of the National Emergency Medical Center via KakaoTalk mobile instant messenger function, which is widely used in Korea, as well as through landline. The messenger system was first used during the disaster response led by the temporary situation room. Officials of the Ministry of Health and Welfare, situation room, emergency medical information center, public health center, on-site DMAT personnel, and the fire department personnel of the Ministry of Public Safety and Security jointly shared all the information including the status of patient visits per hospital and the status of patient treatment in the advanced medical post. The Trunked Radio System is the official means of communication during a disaster. However, it was unavailable due to network problems.

Although the transfer guidelines for critical patients have been formulated and delivered to the field by public health authorities, there was no transfer plan distributed for the mildly wounded patients. Except for several patients who received field triage by medical staff, most patients were transported to the hospitals selected by the private ambulance services, hospital ambulances, and paramedics of fire stations. Over half (56.8\%) of the patients (88/155) were transported to the closest 2 hospitals (Fig. 3). The percentage of patients transferred by the fire station and private ambulances was $51.1 \%(23 / 45)$ and $31.1 \%(14 / 45)$, respectively, for hospital A, and 53.5\% (23/43) and 44.2\% (19/43), respectively, for hospital B. Fire station ambulances contributed more towards unbalanced patient transfer.

\section{Inpatient care in the hospital}

Compared to the large hospitals with DMATs and level 1 trauma centers, which received delayed notification of the disaster (Fig. 1), most of the small- and medium-sized hospitals in Ulsan and Gyeongju region became aware of the incident within 30 minutes through requests from the fire department to send their hospital ambulances to the scene. In the case of the closest 2 hospitals, there was more than 1 hour between disaster notification and patient arrival. This provided time to increase the number of available medical staff and secure additional space for treatment. Reinforcement of nursing resources was easily done because it coincided with the change of nursing shift. Gyeongju regional hospitals also had about 2 hours of preparation time.

Hospitals treating the patients were analyzed according to their capability of providing EMS. The 12 facilities comprised 1 regional emergency medical center designated by the Ministry of Health and Welfare, 3 local emergency medical centers designated by the governor of the province, 4 local emergency medical facilities designated by the mayor, and 4 registered emergency response institutions. One of the hospitals that received the victims was located $60.1 \mathrm{~km}$ away from the resort because the location was close to the residence of the patients. Locations of the hospitals are shown in Fig. 3. Details regarding patient admission are presented in Table 4. Of the 155 patients, 108 were discharged after examination, 11 were hospitalized, and 18 were transferred to other hospitals. The mean \pm standard deviation (SD) time in the emergency department was $2.4 \pm 2.6$ hours.

Most injuries involved the head (28.4\%), followed by lower extremities (27.1\%), back (21.9\%), upper extremities (13.5\%), chest (10.3\%), neck (9.0\%), and other locations (11.0\%). Multiple wounds were recorded as duplicates. The investigations involved radiography $(72.9 \%)$, computed tomography $(18.1 \%)$, electrocardiogram $(7.1 \%)$, laboratory tests $(1.9 \%)$, and others $(0.6 \%)$. More than 2 tests per patient were recorded as duplicates.

Treatment typically included analgesia and trauma care. Administration of analgesics was most common (54.2\%) and trauma care, such as wound care and fixation, was given to $27.7 \%$ of the cases. More than 2 treatments were recorded as duplicates. Surgery was performed in 3 out of 155 patients. One patient underwent tendon and ligament subcutaneous adiabatic surgery under local anesthesia, 1 underwent a damage control surgery for major trauma, and 1 underwent osteoplastic craniotomy and cranioplasty.

The injury severity of the patient was calculated as per the EMR ISS using ICD-10 codes. The mean \pm SD EMR ISS of the 155 patients was $8.3 \pm 7.4$ points. The score was $<8$ for 56 patients (46.7\%), 9-15 for 52 (43.3\%), 16-25 for 11 (9.2\%), and > 26 for 
Table 4. Patient admission details from emergency medical institutes

\begin{tabular}{|c|c|c|c|c|c|c|c|c|}
\hline $\begin{array}{l}\text { Emergency medical institute } \\
\text { classification }\end{array}$ & Hospitals & $\begin{array}{l}\text { Distance } \\
(\mathrm{km})^{\mathrm{a})}\end{array}$ & $\begin{array}{c}\text { No. of } \\
\text { patients (\%) }\end{array}$ & \multicolumn{5}{|c|}{ ER treatment results } \\
\hline Regional emergency medical center & Hospital E & 28.5 & $2(1.3)$ & 0 & 0 & 1 & 1 & 0 \\
\hline \multirow{2}{*}{ Local emergency medical center } & Hospital C & 19.5 & $6(3.9)$ & 6 & 0 & 0 & 0 & 0 \\
\hline & Hospital J & 60.1 & $16(10.3)$ & 11 & 0 & 5 & 0 & 0 \\
\hline \multirow[t]{2}{*}{ Local emergency medical facilities } & Hospital L & 38.5 & $1(0.7)$ & 0 & 0 & 0 & 0 & 1 \\
\hline & Hospital B & 13.7 & $43(27.7)$ & 38 & 5 & 0 & 0 & 0 \\
\hline \multirow[t]{4}{*}{ ER registered institutions } & Hospital G & 35.1 & $8(5.2)$ & 7 & 1 & 0 & 0 & 0 \\
\hline & Hospital H & 34.5 & $7(4.5)$ & 0 & 7 & 0 & 0 & 0 \\
\hline & Hospital I & 34.7 & $6(3.9)$ & 0 & 5 & 0 & 1 & 0 \\
\hline & Hospital A & 8.3 & 45 (29.0) & 32 & 0 & 0 & 7 & 6 \\
\hline
\end{tabular}

ER, emergency room.

${ }^{a}$ The distance is calculated by the distance traveled by car, and not the straight-line distance.

Table 5. Diagnoses of deceased victims

\begin{tabular}{ccl}
\hline Number & Hospital & \multicolumn{1}{c}{ Diagnosis } \\
\hline 1 & Hospital A & Lung contusion \\
2 & Hospital A & Skull deformity, chest contusion \\
3 & Hospital A & Multiple fractures of the ribs, hemothorax \\
4 & Hospital A & Multiple fractures of the ribs, hemothorax \\
5 & Hospital A & Multiple fractures of the ribs, hemothorax \\
6 & Hospital I & No data \\
7 & Hospital E & Traumatic asphyxia \\
8 & Hospital F & Death on arrival (described in the medical record as head \\
& & injury, right sided chest bruising, left sided lower chest \\
& & bruising) \\
9 & Hospital A & First and second lumbar fracture, dislocation \\
10 & Hospital A & Unknown, right lung congestion \\
\hline
\end{tabular}

$1(0.8 \%)$. The patient with the highest EMR ISS (65) had been transported directly to the level I trauma center; the ISS of this patient was 41 .

The exact cause of death of the 10 victims who died in the roof collapse could not be determined because autopsies were not performed. Additionally, due to lack of records of the field rescue time for the deceased, judging the number of preventable deaths was impossible. Diagnoses of the deceased victims are summarized in Table 5.

\section{DISCUSSION}

This was a mass casualty incident with at least 155 casualties. Field triage and distribution of transportation at the site were not properly conducted. Although, these problems have been pointed out in the aftermath of multiple mass casualty incidents, ${ }^{3,5,8}$ the situation has not improved. As shown in Table 4, about half of the patients were transported to the closest hospitals, which were poorly equipped to handle the injured. The most severely injured patient was transported directly to a level 1 trauma center based on the judgment of the on-site DMAT personnel and not the fire department personnel. Two severely injured patients were misdiagnosed or undertreated by the first emergency department and proper diagnosis and surgery was performed after the patients were transferred to another regional level 1 trauma center.

The biggest obstacle in the distribution of transport was a lack of patient transportation command by the field command post. Each ambulance had come from the nearest hospitals without knowing the overall transportation status, similar to the situation in previous mass casualty incidents. ${ }^{8}$ To improve this situation, the fire department suggested reinforcement of the emergency medical personnel to the field command post for triage, and managed the transport of patients during the initial stage of the incident until the arrival of DMATs. ${ }^{14}$ The fire department and Ministry of Health and Welfare officials proposed that the DMATs or the public health center personnel should manage this role immediately at the scene in cooperation with the fire department personnel. ${ }^{14,15}$ For rapid mobilization of DMATs, the proposed plans suggest decreasing the time required to reach the scene by increasing the numbers of DMATs and designating more DMAT dispatch hospitals. $^{15}$

We propose further improvement plans. First, to improve the disaster medical response capacity of the paramedics of fire department, it is necessary to strengthen triage training. ${ }^{16,17}$ Second, for rapid mobilization and strengthening the capability of DMATs, it is necessary to implement a hospital-based ambulance dispatch system. ${ }^{18}$

Another major problem is the lack of cooperation between the 
fire department and medical staff at the scene. Especially, disputes regarding the location of advanced medical posts are usu$\mathrm{al}_{1},{ }^{3,7}$ and were repeated in the latest disaster. The advanced medical post is a major element of the field disaster response system, and is legally required..$^{19}$ However, it continues to be ignored in mass casualty incidents.

Implementation of joint training of the personnel of public health centers, hospitals, and fire stations was previously suggested. ${ }^{15}$ In addition, we suggest organizing a consultative body comprising fire stations, public health centers, and hospitals for every region, and holding frequent meetings between them.

Late dispatch of DMATs is another issue observed in previous disasters. ${ }^{5-8}$ In previous cases, the propagation time of the situation was delayed; however, in this case, mobilization of the DMATs took 69 minutes because the decision regarding dispatch from the Ministry of Health and Welfare was delayed. To improve this situation, the Ministry of Health and Welfare delegated the authority of DMAT response decisions to the previously authorized officials of the permanent situation room inside the National Emergency Medical Center. ${ }^{14}$

As a new means of communication, use of mobile instant messenger among disaster responders was the most salient point of this accident. Previous studies reported that the community, government, and rescue teams shared the information regarding disaster planning, response, and recovery using various types of social media, such as Facebook and Twitter. ${ }^{20}$ Efforts for development of a mobile social networking platform for disaster situations had been reported. ${ }^{21}$ However, there are no reports involving total replacement of existing radio technology based wireless communication system with mobile instant messengers. Mobile messenger usage is disadvantageous because the time of transmitting information using text messages is slightly longer than that using voice transmission. However, it has several advantages; sharing visual information in the form of images and video clips is fast and missing information is less because the information remains in the chat window. Since then, this new means of communication has been used in other mass casualty incidents, and has been used officially after the installation of a permanent situation room in the National Emergency Medical Center. Because the current instant messenger was developed for commercial purposes, development of a new platform that addresses hacking problems and has several functions for disaster situations is needed.

The largest limitation of this study is that the information was collected through interviews and relied on the memories of the interviewees. Hence, there could be some errors because of the 5-month lapse between the time of the disaster and interviews. In addition, the suggested improvement plans for the disaster medical response system were based on evaluation of only 1 mass casualty incident.

\section{CONFLICT OF INTEREST}

No potential conflict of interest relevant to this article was reported.

\section{ACKNOWLEDGMENTS}

Thanks to all institutional personnel who provided the materials and responded to the interviews while conducting this study. Especially, thanks to the Ministry of Public Safety and Security, Gyeongju fire station, and the Gyeongju public health center actively supportive to this study, and the 11 hospitals who readily provided medical records in difficult conditions.

\section{REFERENCES}

1. Shin JH, Kim JK, Yeom SL, et al. Injuries and their complications after urban area fires: the dong-incheon live-hof restaurant fire. J Korean Soc Emerg Med 2001;12:338-44.

2. Choi JT, Ahn ME, Ahn HC, et al. Analysis of victims of the fire that broke out at a beer bar in Inchon. J Korean Soc Emerg Med 2001;12:511-7.

3. Cho SJ, Yeom SR, Jeong JW. Suggestion for maintaining coordinated disaster response: review of disaster response to the air China aircraft crash near Kimhae airport. J Korean Soc Emerg Med 2003;14:9-16.

4. Chung JM, Seol DH, Park JB, et al. Analysis of transportation of victims of the subway fire in Daegu. J Korean Soc Emerg Med 2003;14:514-21.

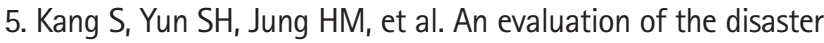
medical system after an accident which occurred after a bus fell off the Incheon bridge. J Korean Soc Emerg Med 2013;24: $1-6$.

6. Jang B, Cho J, Kim J, et al. Disaster medical responses to the shelling of Yeonpyeong Island. J Korean Soc Emerg Med 2013; 24:439-45.

7. $\mathrm{Ko} \mathrm{HJ}$, Lee $\mathrm{KH}$, Kim $\mathrm{OH}$, et al. Experiences of a disaster medical assistant team in the Chun-cheon landslide disaster. J Korean Soc Emerg Med 2013;24:493-9.

8. Chae H, Kim GB, Park WN, et al. Experiences of disaster medical response system in a fire at Goyang bus terminal. J Korean Soc Emerg Med 2015;26:149-58.

9. Go SJ. 40 patients were transported to 10-bed emergency department: non-prepared disaster. Munhwailbo. 2014 Feb 19 
[cited $2015 \mathrm{Jul}$ 24]. Available from: http://www.munhwa.com/ news/view.html?no = 2014021901070527089002.

10. Park GS. Gaps in disaster preparedness. KBS News. $2014 \mathrm{Feb}$ 19 [cited 2016 Apr 15]. Available from: http://news.kbs.co.kr/ news/view.do?ncd $=2812197$.

11. Gyeongju Fire Station. Report on emergency rescue activities: Mauna Ocean Resort gymnasium collapsing. Gyeongju: Gyeongju Fire Station; 2014.

12. National Emergency Medical Center. Report on disaster medical response of Gyeongju Mauna Ocean Resort gymnasium collapsing. Seoul: National Emergency Medical Center; 2014.

13. Kim J, Shin SD, Im TH, et al. Development and validation of the excess mortality ratio-adjusted injury severity score using the international classification of diseases 10th edition. Acad Emerg Med 2009;16:454-64.

14. Ministry of Public Safety and Security. Plans for follow-up measures after Gyeongju Mauna Ocean Resort gymnasium collapsing: strengthening the emergency rescue capacity at disaster scene. Seoul: Ministry of Public Safety and Security; 2014.

15. Ministry of Health and Welfare. Emergency medical support guidelines for large-scale casualties occurring accidents. Se- jong: Ministry of Health and Welfare; 2015.

16. Risavi BL, Salen PN, Heller MB, Arcona S. A two-hour intervention using START improves prehospital triage of mass casualty incidents. Prehosp Emerg Care 2001;5:197-9.

17. Deluhery MR, Lerner EB, Pirrallo RG, Schwartz RB. Paramedic accuracy using SALT triage after a brief initial training. Prehosp Emerg Care 2011;15:526-32.

18. Baker DJ, Telion C, Carli P. Multiple casualty incidents: the prehospital role of the anesthesiologist in Europe. Anesthesiol Clin 2007;25:179-88.

19. Law on Emergency Rescue Response Activities and Field Command, No. 1153 (April 3, 2015).

20. Houston JB, Hawthorne J, Perreault MF, et al. Social media and disasters: a functional framework for social media use in disaster planning, response, and research. Disasters 2015;39: $1-22$.

21. Hu $X$, Leung VCM, Du W, Seet BC, Nasiopoulos P. A serviceoriented mobile social networking platform for disaster situations. In: IEEE Computer Society. 2013 46th Hawaii International Conference on System Sciences; 2013 Jan 7-10; Maui, HI, USA. Washington, DC: IEEE Computer Society; 2013. p.13645. 